\title{
Underwater full-thickness resection of a duodenal bulb gastrointestinal stromal tumor with OverStitch defect repair
}

A 61-year-old man was referred to our institute for endoscopic ultrasound (EUS) evaluation of a subcentimeter subepithelial lesion of the duodenal bulb. Ultrasound imaging showed a homogeneous, hypoechoic lesion of $15 \mathrm{~mm}$ in diameter in the fourth layer of the inferior wall of the duodenal bulb ( $\triangleright$ Fig.1a,b). EUSguided fine needle aspiration showed a gastrointestinal stromal tumor (GIST) and a computed tomography scan confirmed only a localized lesion ( $\triangleright$ Fig. $1 \mathbf{c}$ ). The growth in size of the GIST with respect to the previous examination was an indication for resection, which remains the only modality that can offer permanent cure of GISTs, and avoid tumor rupture and injuries to the pseudocapsule [1].

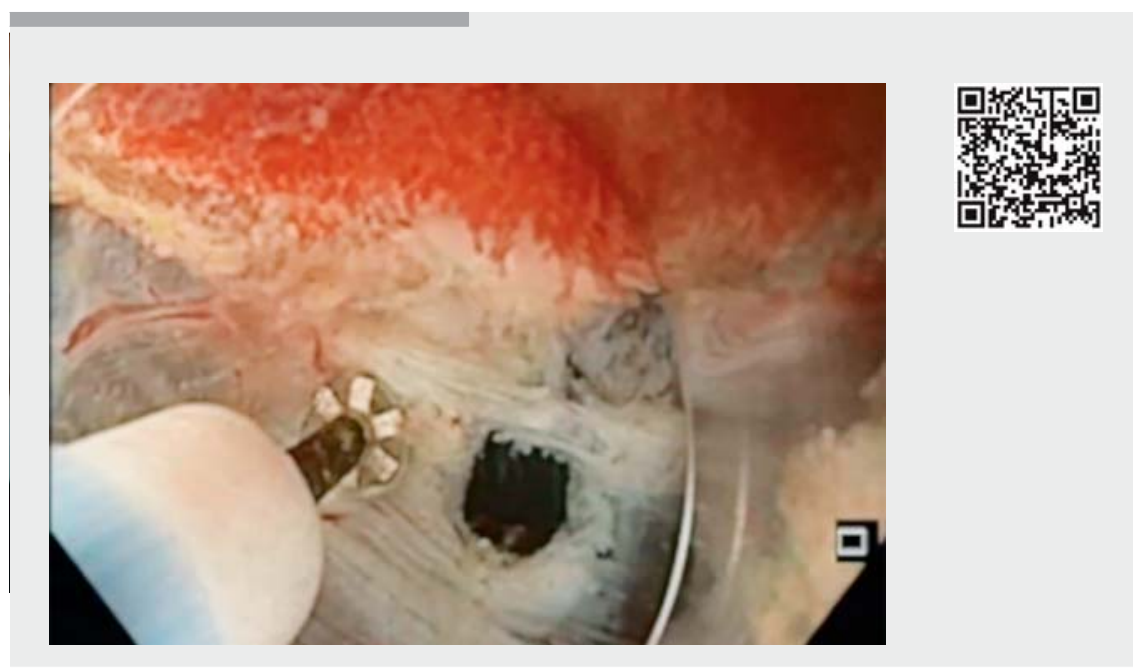

Video 1 A gastrointestinal stromal tumor of the duodenal bulb is resected with a fullthickness mini-invasive endoscopic approach, with the defect being closed using the OverStitch device.

Given the wishes of the patient and in order to avoid major surgery, a multidisciplinary team (endoscopist, oncologist, and surgeon) proposed an endoscopic mini-invasive approach. The procedure was performed with the patient under general anesthesia and with the administration of prophylactic antibiotics. Dissection was performed using an O-type HybridKnife (Erbe Elektromedizin, Germany) and we infused only saline solution into the lumen in order to prevent retroperitoneal $\mathrm{CO}_{2}$ leakage and the consequent subcutaneous emphysema. We performed a full-thickness resection with the aim of achieving a radical oncological resection ( $\downarrow$ Video 1 ). The excision resulted in a complete duodenal wall defect, about $25 \times 25 \mathrm{~mm}$ ( $\triangleright$ Fig. 2), which was closed with three endosutures placed using the OverStitch endoscopic suturing system (Apollo Endosurgery, USA).

In the post-procedural phase, the patient developed pain in the hypochondrium that was easily controlled with a single dose of ibuprofen; oral intake was restarted in the fourth postoperative day. In the following 2 months of follow-up, the patient remained asymptomatic.
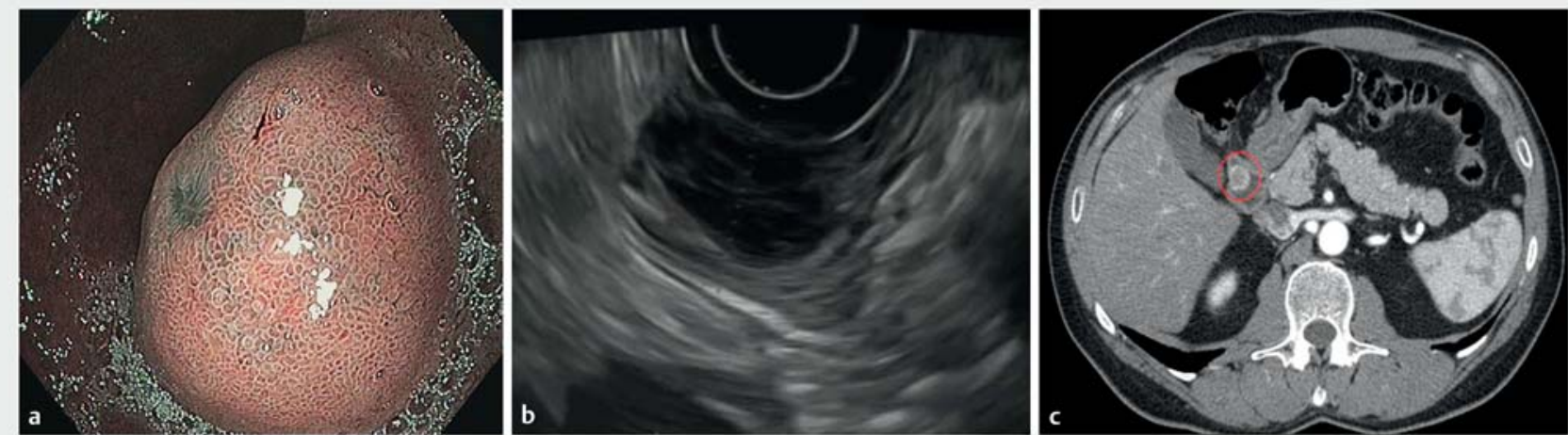

- Fig. 1 Images showing a lesion of the duodenal bulb: a on magnifying endoscopy with narrow-band imaging (NBI), which revealed a subepithelial lesion of the duodenal bulb with an erosion on the top; $\mathbf{b}$ on endoscopic ultrasound, which showed a localized subepithelial lesion; c on computed tomography, which confirmed a localized subepithelial lesion (red ring) starting from the muscular layer. 


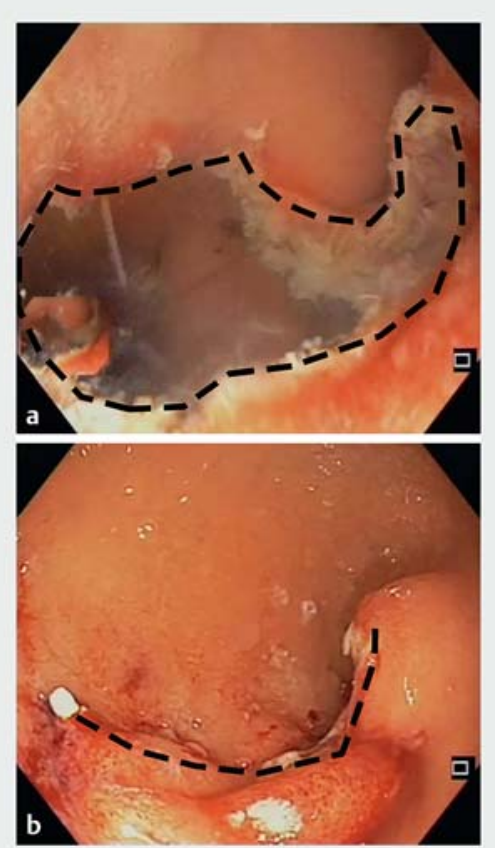

- Fig. 2 Endoscopic images showing: a the duodenal wall defect (black circular dashed line) after the full-thickness resection; $\mathbf{b}$ final apposition of the tissue margins (black linear dashed line) after endoluminal sutures had been placed.

In conclusion, endoscopic full-thickness resection of a duodenal GIST appears to be safe, even if skill-demanding, and can be a valid mini-invasive alternative to surgery.

Endoscopy_UCTN_Code_TTT_1AO_2AG

\section{Competing interests}

None

The authors

Antonino Granata ${ }^{1}$, Michele Amata ${ }^{1}$, Dario Ligresti ${ }^{1}$, Pasquale Bonsignore ${ }^{2}$, Sergio Li

\section{Petri², Mario Traina}

1 Digestive Endoscopy Service, Department of Diagnostic and Therapeutic Services, IRCCSISMETT, Palermo, Italy

2 Abdominal Surgery and Organ Transplantation Unit, Department for the Treatment and Study of Abdominal Diseases and Abdominal Transplantation, IRCCS-ISMETT, Palermo, Italy

\section{Corresponding author}

\section{Antonino Granata, MD}

Endoscopy Service, IRCCS-ISMETT, Via

Tricomi 5, 90127 Palermo, Italy

Fax: +39-091-2192400 (specify Endoscopy

Service)

agranata@ismett.edu

\section{Reference}

[1] Nishida T, Blay JY, Hirota $S$ et al. The standard diagnosis, treatment, and follow-up of gastrointestinal stromal tumors based on guidelines. Gastric Cancer 2016; 19: 3-14

\section{Bibliography}

DOI https://doi.org/10.1055/a-0881-2702

Published online: 2.5.2019

Endoscopy 2019; 51: E207-E208

(c) Georg Thieme Verlag KG

Stuttgart · New York

ISSN 0013-726X

\section{ENDOSCOPY E-VIDEOS}

https://eref.thieme.de/e-videos

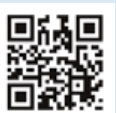

Endoscopy E-Videos is a free access online section, reporting on interesting cases and new

techniques in gastroenterological endoscopy. All papers include a high quality video and all contributions are freely accessible online.

This section has its own submission website at

https://mc.manuscriptcentral.com/e-videos 